Matyushkin, E. N., Pikunov, D. G., Dunishenko, Y. M., Miquelle, D. G., Nikol.aev, I. N., Smirnov, E. N., Salkina, G., Abramov, V. K., Basylnikov, V., Yudin, V. G. \& KorkishKo, V. G. (1996): Numbers, distribution, and habitat status of the Amur tiger in the Russian Far East: express report. USAID Russian Far East Environmental Policy and Technology Project Report. [In Russian and English.]

Mills, J. \& JACKsON, P. (1994): Killed for a cure. Cambridge: TRAFFIC International.

Morsiach, D. (1987): Cheetahs in Namibia. Cat News 6: 25-26.

Nowfill, K. \& JACKson, P. (1996): Wild cats: status survey and conservation action plan. Gland: IUCN.

O'Brien, S., WiLDT, D. E. \& Bush, M. (1986): The cheetah in genetic peril. Scientific American 254(5): 68-76.

O'Brien, S., Wildt, D. E., Bush, M., Caro, T. M., FitzGibbon, C., Aggundey, I. \& Leaky, R. E. (1987): East African cheetahs: evidence for two population bottlenecks? Proceedings of the National Academy of Sciences of the USA 84: 508-511.

RABINowITZ, A. R. (1993): Estimating current abundance of the Indo-Chinese tiger in Thailand. Biological Conservation 65: 213-217.

SchwanN, T. (Unpublished): A preliminary report on the distribution of tigers in Thailand. Unpublished report to Global Tiger Forum, Delhi, 1994.

Wartaputra, S., Soemarna, K., Ramono, W., Manansang, J. \& Tilson, R. (1994): Indonesian Sumatran tiger conservation strategy. Jakarta: Directorate General of Forest Protection and Nature Conservation.

Wozencraft, W. C. (1993): Order Carnivora. In Mammal species of the world (2nd edn): 286-346. Wilson, D. E. \& Reeder, D. M. (Eds). Washington, DC: Smithsonian Institution.

Manuscript submitted 16 January 1996; revised 19 November 1996

\title{
History of the Cheetah
}

\section{Acinonyx jubatus \\ in zoos 1829-1994}

\author{
LAURIE MARKER-KRAUS \\ Cheetah Conservation Fund, PO Box 247, Windhoek, Namibia
}

Since 1829 the African Cheetah Acinonyx jubatus has been exhibited in over 373 zoological facilities. As at 31 December 1994 the international captive population was 1218 animals of which $880(72 \%)$ were captive-bred and $338(28 \%)$ were wild-caught. The steady increase in the captive population is a result of captive breeding, co-operative captive-management programmes and importation from the wild. Of facilities holding Cheetah $26 \%$ (96) have bred the species, $15 \%$ of which have bred continuously producing $63 \%(n=1580)$ of all cubs born in captivity. Although the number of facilities breeding Cheetah has increased, in 1994 only 10\% of them reported successful reproduction. The $\mathrm{N}_{e}$ has increased gradually and in 1994 was equivalent to $17 \%$ of the captive population. Of 1564 animals that have been imported, c. 20\% $(n=308)$ have reproduced and in 1994155 have living descendants in the captive population. Except for a few East African Cheetah Acinonyx jubatus raineyi all of the imported animals are the southern African subspecies Acinonyx jubatus jubatus. There has been an increase in the number of subspecific hybrids in the captive population and between 1990 and 199428 hybrids produced 24"1" (190) of cubs. The captive population is not yet selfsustaining and is maintained by the importation of wild-caught animals. Continued progress can be achieved by implication of a co-ordinated global management programme.

Key-words: captive history, captive-management plans, cheetah, pedigree analysis, registry, reproduction, studbook, zoos

The Cheetah Acinonyx jubatus is markedly different in both anatomy and behaviour from the other 36 felid species. It is the only species in the genus Acinony $x$ and the fastest land mammal.

Cheetahs were widely distributed throughout western Asia and Africa and in 1900 the wild population was estimated to be 100000 animals (Myers, 1975). Today c. 12000 live in 23 African coun- 
tries, with the largest concentration in southern Africa. Less than 200 Cheetahs live in Iran (Kraus \& Marker-Kraus, 1992). Although Cheetahs are widely distributed in Africa, including parts of North Africa, Sahel and eastern and southern Africa, the population continues to decline because of habitat fragmentation (Kraus \& Marker-Kraus, 1992). The Cheetah is classified as Vulnerable or Endangered throughout its range and is on CITES Appendix 1 (CITES, 1984, 1992; Jackson, this volume).

Wild Cheetahs are threatened by loss of habitat resulting from increased agriculture and a decline in numbers of prey species (Wrogemann, 1975; Hamilton, 1986; Myers, 1986; Morsbach, 1987; Wilson, 1987; Marker-Kraus \& Kraus, 1990 , this volume). The availability of firearms has resulted in increased poaching of Cheetah and their prey (Kraus \& MarkerKraus, 1992). Most Cheetahs are found outside reserves because in protected areas they are in competition with larger predators such as Lions Panthera leo and Hyenas Parahyaena brunnea (Caro, 1987; Morsbach, 1987; Laurenson, 1991; Mills, 1991; Kraus \& Marker-Kraus, 1992; Marker-Kraus \& Kraus, this volume). Namibia has the largest remaining population of free-ranging Cheetahs, estimated at 2500 animals (Morsbach, 1987; Kraus \& Marker-Kraus, 1992; Marker-Kraus et al., 1996; Marker-Kraus \& Kraus, this volume).

The decline in wild Cheetah populations means that the animals which do survive originate from a less diverse gene pool. The genetic structure of Cheetah populations, compared to other felids, is markedly depleted in genetic variability (O'Brien et al., 1983, 1985, 1987; MenottiRaymond \& O'Brien, 1993). Genetic uniformity may affect reproductive efficiency, infant mortality and disease susceptibility (O'Brien et al., 1983, 1985, 1987; Wildt et al., 1983, 1987, 1993; Evermann et al., 1988; Marker \& O’Brien, 1989; Heeney et al., 1990; Junge et al., 1991; MarkerKraus \& Grisham, 1993).

\section{HISTORY WITH HUMANS}

The Cheetah, also called the 'hunting leopard', has the longest hunting association with humans of any animal, with the exception of the dog. The earliest record is from the Sumerians in c. $3000 \mathrm{BC}$ where a leashed Cheetah, possibly with a hood on its head, is depicted on an official seal. The Cheetah was considered to be a goddess in early lower Egypt (Westendorf, 1966).

Cheetahs are the most easily tamed of all the big cats and, in the past, adults were caught, tamed and trained within a few weeks. Emperors kept hundreds of the animals in their stables at any one time. In the 5th century hunting with Cheetahs for sport, or coursing, occurred in Italy. In the 11 th and 12 th centuries Russian princes hunted with Cheetahs and Crusaders saw the species being used to hunt gazelles Gazella spp in Syria and Palestine. Marco Polo reported that hundreds of Cheetahs were kept by Kublai Kahn. Almost all Italian Renaissance courts had Cheetahs as did many of the French courts. Cheetahs were kept by royalty from Ethiopia to China in the 14th, 15th and 16th centuries (Guggisberg, 1975). Prior to the 1950 s there is only one report of a litter born in captivity and that was in the 15 th century at the Palace of Akbar, a Mogul emperor (Guggisberg, 1975).

Because of the continuous drain on wild populations Cheetahs declined throughout Asia. In the early 1900s India and Iran began to import Cheetahs from Africa for hunting purposes (Divyabhanusinh, unpubl.).

By the end of the 19th century Cheetahs were rare in Asia Minor and Arabia. In 1952 the species was declared extinct in India and in 1956 the last Cheetah was reported in Israel (Kraus \& MarkerKraus, 1992). The only confirmed reports of Asian Cheetahs are from Iran where up 
to 200 occur in small isolated populations. Because of the disappearance of larger prey species these animals prey on rabbits (Kraus \& Marker-Kraus, 1992).

\section{CONSERVATION INITIATIVE FOR CAPTIVE CHEETAH}

During the 1980s several conservation initiatives for Cheetah were established including: (1) the development of regional studbooks in North America (Marker, 1983), Japan (Hayashi, 1986) and Great Britain (McKeown, 1992); (2) the development of an international studbook in 1988 (Marker-Kraus, 1990a); (3) the inclusion of the species as a target animal of (a) the Species Survival Plan (SSP) of the American Zoo and Aquarium Association (AZA; formerly AAZPA) in 1984, (b) the European Endangered Species Programme (EEP) of the European Association of Zoos and Aquaria (EAZA), (c) the Australian Species Management Program (AMSP) of the Australasian Regional Association of Zoological Parks and Aquaria (ARAZPA), (d) the Species Survival Committee of the Japanese Association of Zoological Gardens and Aquariums (JAZGA) and (e) the African Preservation Programme (APP) of the Pan African Association of Zoological Gardens, Aquaria and Botanical Gardens (PAAZAB); (4) a Cheetah SSP Research Master Plan which involved implementing a multidisciplinary research programme, to provide a biological explanation for the relatively poor captive breeding (Grisham \& Lindburg, 1988), including research in genetics, captive behaviour and husbandry, reproductive physiology, disease and nutrition (Howard et al., 1992, 1993; Brown et al., 1993; Caro, 1993; Dierenfeld, 1993; Evermann et al., 1993; Laurenson, 1993; Lindburg et al., 1993; Marker-Kraus \& Grisham, 1993; Munson, 1993; Wildt \& Grisham, 1993; Wildt et al., 1993; O'Brien, 1994). These programmes, in conjunction with the IUCN's Conservation Breeding Specialist
Group (CBSG), are working to manage the captive population.

An important aspect of a species conservation programme is the development of a demographic and genetic profile of the captive population. The international studbook, first published in 1989 and updated annually (Marker-Kraus, 1990a,b, 1991, 1992, 1993, 1995, 1996), contains detailed records of all captive Cheetahs. Much of the historic information was collected by $M$. Jones who between 1951 and 1982 visited zoos world-wide and recorded information on Cheetah and other species (McKeever, 1994). This information, with data submitted by zoos and ISIS, has allowed for detailed analysis of the captive population. There are 3381 Cheetahs registered in the international studbook and 673 other animals known from historical records.

Between 1829 and 1994 over 1567 Cheetahs were imported from the wild and exhibited at more than 373 facilities. There were 2517 captive births and 3472 deaths during this time.

\section{THE CAPTIVE CHEETAH POPULATION 1829-1954}

The earliest record of a Cheetah in a zoological collection is in 1829 at The Zoological Society of London (Marker-Kraus, 1990a). This animal lived less than 1 year. Cheetahs were not exhibited again until 1851 at Antwerp, 1852 at Berlin ZG, 1860 at Frankfurt and 1863 at Hamburg. In 1871 Cheetahs were first exhibited in North America at Central Park Zoo, New York. Between 1851 and 1900 only 14 zoos exhibited Cheetahs. Other early facilities holding Cheetah include Cairo in 1900, Basel Zoo in 1910, National Zoo in Washington in 1913, Chicago Lincoln Park in 1914 and St Louis Zoo in 1929.

Between 1829 and 1954139 wild-caught Cheetahs were exhibited at 47 facilities (Table 1). Most of these animals only survived for up to 1 year and in this period there were 115 deaths and no births. 


\begin{tabular}{lccccc}
\hline & $\begin{array}{r}1829- \\
1854\end{array}$ & $\begin{array}{r}1855- \\
1879\end{array}$ & $\begin{array}{r}1880- \\
1904\end{array}$ & $\begin{array}{r}1905- \\
1929\end{array}$ & $\begin{array}{c}1930- \\
1954\end{array}$ \\
\hline Imports & 5 & 1 & 19 & 25 & 89 \\
$\begin{array}{l}\text { Deaths } \\
\text { Animals at start/end } \\
\quad \text { of period' }\end{array}$ & 1 & 1 & 10 & 29 & 73 \\
\hline
\end{tabular}

In 1829 one Cheetah was kept at London Zoo and in 195432 Cheetahs were held at 18 institutions.

Table 1. Number of importations and deaths in the captive Cheetah $A c i-$ nonyx jubatus population between 1829 and 1954; data are as at 31 December for each period.

Although several European zoos began exhibiting Cheetah in the late 1800 s and early 1900 s the species was rarely seen in North American zoos until the 1950s, after which they became one of the major animal exhibits in both Europe and North America (Marker-Kraus, 1990a). As at 31 December 195432 Cheetahs were exhibited at 18 facilities.

\section{THE CAPTIVE CHEETAH POPULATION 1955-1994}

Between 1955 and 19941440 Cheetahs were imported to zoological collections (Table 2). Cheetahs were exported from East Africa, Kenya and Somalia until the late 1960s when they became scarce in these areas (Marker-Kraus, 1990a). Since the 1960 s Cheetah have been exported primarily from Namibia (Marker-Kraus, 1990a). The captive population increased from 33 animals in 1955 to 1218 in 1994 (Fig. 1; Table 2). During this time there were 3436 deaths.

Before 1973 the increase in the captive population was primarily the result of importation (Fig. 2); between 1955 and 1973 there were 549 imports but only 108 births (Table 2). In 197484 Cheetahs were imported which represented $21 \%$ of the total captive population for that year (Fig. 2; Table 2). This was the last large importation of wild-caught Cheetahs because in 1975 CITES legislation resulted in a reduction in the number of imports allowed (CITES, 1984).
From 1973 the number of captive births steadily increased with the exception of two temporary declines in 1977 and 1987 (Fig. 2; Table 2). From 1980 to 1994 (not including 1987) 30 or more litters were born per year. Between 1955 and 1994 2517 cubs were born in 759 litters at 96 facilities (Table 2).

The increase in the captive population was a result of captive breeding, co-operative management programmes and importation from the wild. As at 31 December 1994 the captive population was $1218(612.606)$ of which $880(72 \%)$ were captive-bred and $338(28 \%)$ were wild-caught. These Cheetahs were housed at 211 facilities in 47 countries in eight geographical regions (Table 3 ).

\section{REPRODUCTION}

In 1956 the first authenticated captive birth occurred at Philadelphia Zoo and this pair had a second litter in 1957. Births are also recorded in 1960 at Krefeld, 1962 at Oklahoma and 1967 at Whipsnade. Of 373 facilities which have housed Cheetah only $96(26 \%)$ have reported successful reproduction. Captive births increased gradually until 1974 when 15 collections bred the species, representing $19 \%$ of the facilities holding Cheetahs at that time. It is possible that the increase in breeding in 1974 and 1975 was a result of the high number of wild-caught animals imported at that time $(n=128)$ which represented $30 \%$ of the captive population in 1975 


\begin{tabular}{|c|c|c|c|c|c|c|c|c|c|}
\hline \multirow[t]{2}{*}{ YEAR } & \multirow[t]{2}{*}{ IMPORTS } & \multirow[t]{2}{*}{ LITTERS } & \multirow{2}{*}{$\begin{array}{l}\text { NO. } \\
\text { BORN }\end{array}$} & \multicolumn{3}{|l|}{ DEATHS } & \multirow{2}{*}{$\begin{array}{l}\text { NO. } \\
\text { ANIMALS }\end{array}$} & \multirow{2}{*}{$\begin{array}{l}\text { NO. } \\
\text { INSTIT. }\end{array}$} & \multirow{2}{*}{$\begin{array}{l}\text { No. } \\
\text { INSTIT. } \\
\text { WHICH } \\
\text { BRED }\end{array}$} \\
\hline & & & & TOTAL & $\begin{array}{l}\leqslant 30 \\
\text { DAYS }\end{array}$ & $\begin{array}{l}\geqslant 1 \\
\text { YEAR }\end{array}$ & & & \\
\hline 1955 & 4 & & & 3 & & & 33 & 29 & \\
\hline 1956 & 6 & 1 & 3 & 11 & 3 & 3 & 45 & 30 & 1 \\
\hline 1957 & 8 & 1 & 2 & 6 & & 2 & 52 & 33 & 1 \\
\hline 1958 & 10 & & & 5 & & & 68 & 43 & \\
\hline 1959 & 13 & & & 17 & & & 75 & 48 & \\
\hline 1960 & 11 & 1 & 4 & 12 & 2 & 2 & 91 & 51 & 1 \\
\hline 1961 & 6 & & & 4 & & & 89 & 53 & \\
\hline 1962 & 37 & 2 & 5 & 19 & 5 & 5 & 153 & 102 & 1 \\
\hline 1963 & 17 & 1 & 2 & 23 & 2 & 2 & 165 & 75 & 1 \\
\hline 1964 & 30 & & & 21 & & & 206 & 92 & \\
\hline 1965 & 36 & & & 18 & & & 215 & 87 & \\
\hline 1966 & 40 & 2 & 4 & 31 & & & 276 & 112 & 1 \\
\hline 1967 & 46 & 1 & 3 & 26 & & 1 & 260 & 103 & 1 \\
\hline 1968 & 27 & 2 & 6 & 38 & 1 & 1 & 156 & 57 & 2 \\
\hline 1969 & 39 & 1 & 2 & 10 & & & 184 & 64 & 1 \\
\hline 1970 & 90 & 5 & 11 & 30 & 2 & 2 & 238 & 66 & 4 \\
\hline 1971 & 38 & 5 & 14 & 39 & 4 & 5 & 264 & 71 & 5 \\
\hline 1972 & 34 & 5 & 16 & 33 & 2 & 2 & 304 & 76 & 5 \\
\hline 1973 & 57 & 12 & 36 & 40 & 3 & 7 & 328 & 79 & 9 \\
\hline 1974 & 84 & 23 & 86 & 117 & 24 & 48 & 401 & 80 & 15 \\
\hline 1975 & 44 & 28 & 102 & 135 & 19 & 31 & 423 & 87 & 16 \\
\hline 1976 & 57 & 28 & 106 & 107 & 26 & 33 & 503 & 98 & 14 \\
\hline 1977 & 66 & 18 & 58 & 58 & 10 & 11 & 573 & 107 & 11 \\
\hline 1978 & 49 & 25 & 80 & 87 & 17 & 22 & 625 & 108 & 14 \\
\hline 1979 & 37 & 23 & 66 & 80 & 13 & 20 & 658 & 117 & 13 \\
\hline 1980 & 34 & 35 & 113 & 144 & 39 & 51 & 711 & 127 & 16 \\
\hline 1981 & 21 & 30 & 96 & 147 & 28 & 38 & 718 & 138 & 18 \\
\hline 1982 & 40 & 33 & 111 & 169 & 35 & 58 & 760 & 137 & 19 \\
\hline 1983 & 43 & 30 & 115 & 160 & 17 & 39 & 788 & 142 & 15 \\
\hline 1984 & 28 & 33 & 120 & 157 & 14 & 46 & 848 & 150 & 21 \\
\hline 1985 & 40 & 36 & 97 & 170 & 17 & 36 & 856 & 152 & 19 \\
\hline 1986 & 54 & 34 & 112 & 165 & 23 & 33 & 879 & 159 & 17 \\
\hline 1987 & 29 & 24 & 79 & 124 & 12 & 17 & 885 & 170 & 14 \\
\hline 1988 & 59 & 37 & 120 & 163 & 25 & 36 & 940 & 179 & 15 \\
\hline 1989 & 32 & 42 & 136 & 186 & 34 & 39 & 953 & 174 & 23 \\
\hline 1990 & 31 & 38 & 128 & 206 & 19 & 29 & 930 & 165 & 24 \\
\hline 1991 & 27 & 48 & 172 & 166 & 31 & 43 & 1040 & 184 & 25 \\
\hline 1992 & 31 & 56 & 181 & 208 & 44 & 61 & 1119 & 192 & 29 \\
\hline 1993 & 44 & 56 & 192 & 170 & 32 & 46 & 1168 & 204 & 32 \\
\hline 1994 & 41 & 43 & 139 & 131 & 34 & 37 & 1218 & 211 & 21 \\
\hline TOTAL & 1440 & 759 & 2517 & 3436 & 537 & 806 & & & \\
\hline
\end{tabular}

Table 2. Population growth of the captive Cheetah population 1955-1994.

(Table 2). In $199316 \%$ of facilities bred Cheetah, although by 1994 only 10\% reported breeding success.

Most breeding has occurred at a few zoos. Over $45 \%(n=44)$ of facilities which have bred Cheetah have had limited success over a brief period with a particular $\delta$ or $q$ or both. Forty facilities $(42 \%)$ have bred for only 1 or 2 years and since 1990 44 facilities $(46 \%)$ have not bred and half of these no longer hold the species. Of the facilities which have bred Cheetah 52 (54\%) have continued to breed in the 


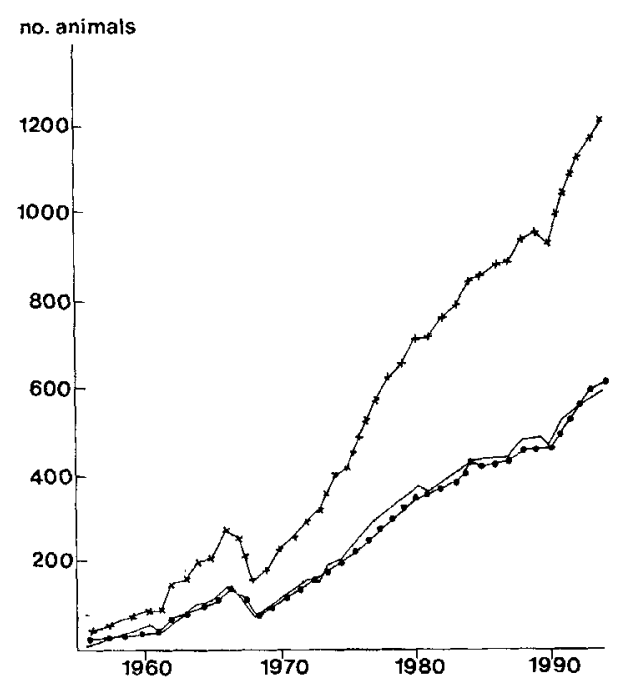

Fig. 1. Number of Cheetahs Acinonyx jubatus in 373 facilities from 1955 to 1994; crosses total; dots $3 \hat{j}$; line

1990s and 25 only began breeding in the 1990s.

Fourteen facilities $(15 \%)$ have had continuous breeding success and have produced more than 50 cubs each with multiple sires and dams, producing $63 \%$ $(n=1580)$ of all cubs born in captivity. All of these facilities have continued to breed in the 1990s.

Since $1956594(298.296)$ animals have bred successfully, of which 308 (156.152) were wild-caught and 286 (142.144) were captive-born. Analysis of breeding

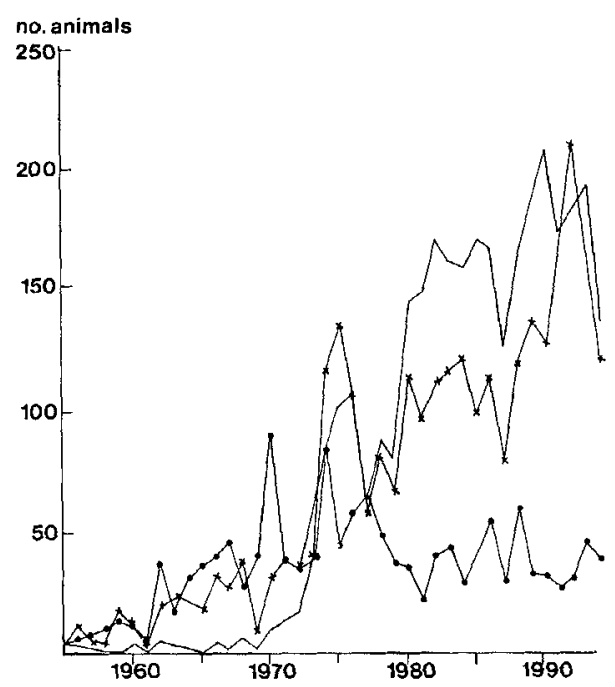

Fig. 2. Time course of dots imports, line captive births and crosses deaths of Cheetahs between 1955 and 1994.

animals has revealed that: (1) the mean number of litters was 2.67 for each breeding animal (range 1-14); (2) the mean number of cubs per breeding animal was 9.07 (range 1-53) (Table 4). Using a two-tailed $T$-test assuming equal variance is applied, there is no statistically significant difference in these parameters when wild-caught breeding animals, past and present, are compared to captive-born breeding animals.

The age distribution of all breeding animals by sex for first and last litters is

\begin{tabular}{|c|c|c|c|c|}
\hline REGION & $\begin{array}{l}\% \text { CAPTIVE } \\
\text { POPULATION }\end{array}$ & $\begin{array}{l}\text { NO. } \\
\text { ANIMALS }\end{array}$ & $\begin{array}{l}\text { No. } \\
\text { COUNTRIES }\end{array}$ & $\begin{array}{l}\text { NO. } \\
\text { FACILITIES }\end{array}$ \\
\hline Southern Africa & 28 & 168.171 & 4 & 37 \\
\hline North America & 27 & 174.149 & 2 & 48 \\
\hline Europe & 23 & 134.146 & 17 & 72 \\
\hline Far East & 10 & 59.61 & 8 & 16 \\
\hline United Kingdom & 6 & 37.38 & 3 & 15 \\
\hline Central and South America & 3 & 14.21 & 4 & 9 \\
\hline North-East Africa, Middle East and India & 2 & 14.16 & 7 & 9 \\
\hline Australia and New Zealand & 1 & 12.4 & 2 & 5 \\
\hline TOTAL & & 612.606 & 47 & 211 \\
\hline
\end{tabular}

Table 3. Regional distribution of the captive Cheetah population as at 31 December 1994. 
given in Fig. 3. Age at first litter for wildcaught and captive-born animals ranges between 18 months and 15 years (Table 4). For both sexes most successful breeding occurs between 3 and 9 years of age (Figs 3 and 4). These data are relevant in assessing the age structure of the captive population (Fig. 5). As at 31 December 1994179 animals (15\%) were over the optimal reproductive age ( $\geqslant 10$ years old), $765(63 \%)$ were between 3 and 9 years old and $274(22 \%)$ were subadults. Of the 203 (102.101) breeding animals alive as at 31 December $199429 \%$ (59) were over the optimal reproductive age $(\geqslant 10$ years) (Fig. 6$)$.

The mean age for first litters was 4.85 years for +9 and 5.18 for $\delta \sigma^{*}$. The average age at last litter for both $\delta \delta^{\star}$ and fo was 6.96 years (Table 4 ). Using a twotailed $T$-test assuming equal variance is applied, wild-caught breeding $0 \hat{\sigma}$ and 우, past and present, were compared to captive-born breeding $\delta \sigma^{\star}$ and $\phi \circ$. A significant difference $(P \leqslant 0.05)$ was found in the age at first litter for 90 and the age of last litter for $\delta \star s$. The mean age at first litter for wild-caught 9 우 was 5.06 years, compared to 4.64 years for captive-born 우 $(P=0.015)$. Also of significant difference was the age of last litter for wild-caught ot, 7.67 years, compared to 6.38 years for captive-born of $(P=0.002)$. These differ-

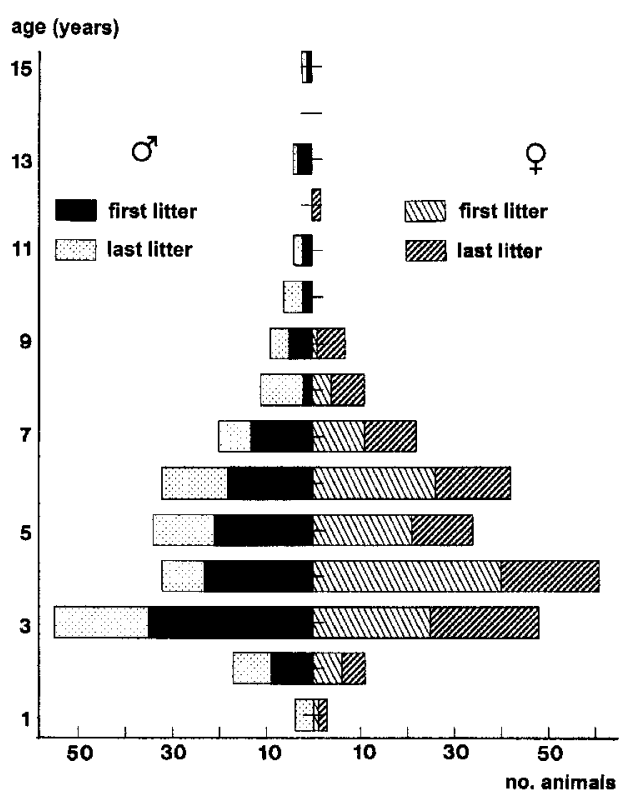

Fig. 3. Age distribution of successfully breeding $\delta$ and $q$ Cheetahs at first and last litters.

ences may be the result of the estimated ages of wild-caught animals; because of their living conditions, wild-caught Cheetahs may appear older than captive-born animals of the same age. However, these data may be significant and further investigation is necessary.

In 1994 only 35.39 Cheetahs actually bred although there were 102.101 proven

\begin{tabular}{lllll}
\hline & WILD $\delta$ & CAPTIVE $\delta$ & WILD $q$ & CAPTIVE $q$ \\
\hline Age at first litter & & & & \\
Range & $<2-15$ & $2-15$ & $<2-13$ & $<2-9$ \\
Mean & 5.33 & 5.04 & 5.06 & 4.64 \\
Age at last litter & & & & \\
Range & $<2-15$ & $1-15$ & $2-13$ & $<2-13$ \\
Mean & 7.67 & 6.38 & $7 \cdot 16$ & 6.65 \\
No. litters & & & & \\
Range & $1-14$ & $1-13$ & $1-9$ & $1-8$ \\
Mean & 2.77 & 2.63 & 2.62 & 2.66 \\
No. cubs & $1-53$ & $1-40$ & $1-28$ & $1-32$ \\
Range & 9.42 & 8.92 & 8.72 & 9.25 \\
Mean & & & & \\
\hline
\end{tabular}

Table 4. Mean age at first and last litter and number of litters and cubs for captive and wild-caught Cheetah 1956-1994. 


\begin{tabular}{|c|c|c|c|}
\hline YEAR & $\begin{array}{l}\text { NO. CHEETAHS } \\
\text { WHICH BRED } \\
\text { SUCCESSFULLY } \\
\text { DURING YEAR }\end{array}$ & $\begin{array}{l}\text { NO. PROVEN } \\
\text { BREEDERS } \\
\text { ALIVE AT } \\
\text { END OF YEAR }\end{array}$ & $\begin{array}{l}N_{e} \\
(\%)\end{array}$ \\
\hline 1955 & & & \\
\hline 1956 & 1.1 & 1.1 & 4 \\
\hline 1957 & I. 1 & 1.1 & 4 \\
\hline 1958 & & 1.1 & 3 \\
\hline 1959 & & 1.1 & 2 \\
\hline 1960 & 1.1 & 1.1 & 2 \\
\hline 1961 & & 1.1 & 2 \\
\hline 1962 & 1.1 & 2.2 & 3 \\
\hline 1963 & 1.1 & 2.2 & 2 \\
\hline 1964 & & 2.2 & 2 \\
\hline 1965 & & 2.2 & 2 \\
\hline 1966 & 1.1 & 2.2 & 1 \\
\hline 1967 & 1.1 & 2.2 & 2 \\
\hline 1968 & 2.2 & 1.2 & 2 \\
\hline 1969 & 1.1 & 2.3 & 3 \\
\hline 1970 & 4.4 & 2.4 & 2 \\
\hline 1971 & 5.5 & 4.5 & 3 \\
\hline 1972 & 5.5 & 5.7 & 4 \\
\hline 1973 & 10.10 & 12.15 & 8 \\
\hline 1974 & 19.15 & 15.19 & 8 \\
\hline 1975 & 21.20 & 23.26 & 12 \\
\hline 1976 & 16.17 & 27.31 & 12 \\
\hline 1977 & 16.17 & 29.21 & 9 \\
\hline 1978 & 17.21 & 31.35 & 11 \\
\hline 1979 & 16.20 & 32.38 & 11 \\
\hline 1980 & 25.31 & 38.49 & 12 \\
\hline 1981 & 23.26 & 49.53 & 14 \\
\hline 1982 & 25.27 & 43.61 & 13 \\
\hline 1983 & 27.30 & 48.65 & 14 \\
\hline 1984 & 27.33 & 48.71 & 14 \\
\hline 1985 & 25.30 & 48.72 & 14 \\
\hline 1986 & 24.30 & 47.68 & 13 \\
\hline 1987 & 15.19 & 40.63 & 11 \\
\hline 1988 & 26.31 & 39.65 & 10 \\
\hline 1989 & 32.36 & 45.71 & 12 \\
\hline 1990 & 28.35 & 52.72 & 13 \\
\hline 1991 & 37.47 & 64.86 & 14 \\
\hline 1992 & 45.53 & 88.102 & 17 \\
\hline 1993 & 46.45 & 110.116 & 19 \\
\hline 1994 & 35.39 & 105.103 & 17 \\
\hline
\end{tabular}

Table 5. Number of Cheetahs which bred successfully each year and the number of proven breeders alive at the end of each year between 1955 and 1994. Effective breeding size for the population $\left(N_{e}\right)$ is given as a percentage of the captive population.

breeding animals alive; that is animals that had successfully produced cubs at least once (Table 5). These values permitted the calculation of an effective breeding size $\left(\mathrm{N}_{\mathrm{e}}\right)$ for the population using the formula:
$\mathrm{N}_{\mathrm{e}}=(4 \times \mathrm{M} \times \mathrm{F}) \div(\mathrm{M}+\mathrm{F})=202.9$

where $\mathbf{M}$ is the number of breeding $\delta^{\circ} \sigma^{\circ}$ and $\mathrm{F}$ is the number of breeding +क. $\mathrm{N}_{\mathrm{c}}$ is equivalent to $17 \%$ of the captive population. Over the past 40 years, although the number of Cheetah births has risen, $\mathrm{N}_{\mathrm{e}}$ has only increased gradually and was higher in 1993 (110.116 proven breeders, $\mathrm{N}_{\mathrm{e}}=225.8,19 \%$ of total population in 1993, $n=1168$ ) (Table 5). The chronically low $\mathrm{N}_{\mathrm{e}}$ indicated that the captive population falls well below the accepted definition of a viable population (Soulé et al., 1986).

\section{SURVIVORSHIP AND MORTALITY}

The growth pattern of a population is derived from the combination of reproduction and relative survival. Cheetah mortality has increased gradually over the 40 years since captive breeding began and clearly correlates with population growth (Figs 1 and 2). An analysis of age at death indicated that the most vulnerable age was $0-1$ month old, (25\% of all deaths) (Fig. 7). After the age of 2 years there is a clear demarcation between the age of death for wild-caught animals and captive-bred animals.

The combined incidence of infant mortality in captive-born animals between 1956 and 1994 was $21 \%$ at 1 month and $28 \%$ at $\leqslant 6$ months of age. These are high values compared to other non-inbred zoo species (Ralls \& Ballou, 1982; O'Brien et al., 1985). Infant mortality varied widely among institutions $(0-100 \%)$ and also between years (Table 2). The high incidence of infant mortality may be the result of an ancestral genetic homogenization event that purged large portions of genetic variation from the species (O'Brien et al, 1985, 1987; Menotti-Raymond \& O'Brien, 1993) and captive husbandry problems (Lindburg, 1991; Caro, 1993; Laurenson, 1993; Lindburg et al., 1993). In captiveborn animals mortality after the first year was almost equally distributed from 2 to 13 years of age. With few exceptions, mortality in wild-caught animals was almost 

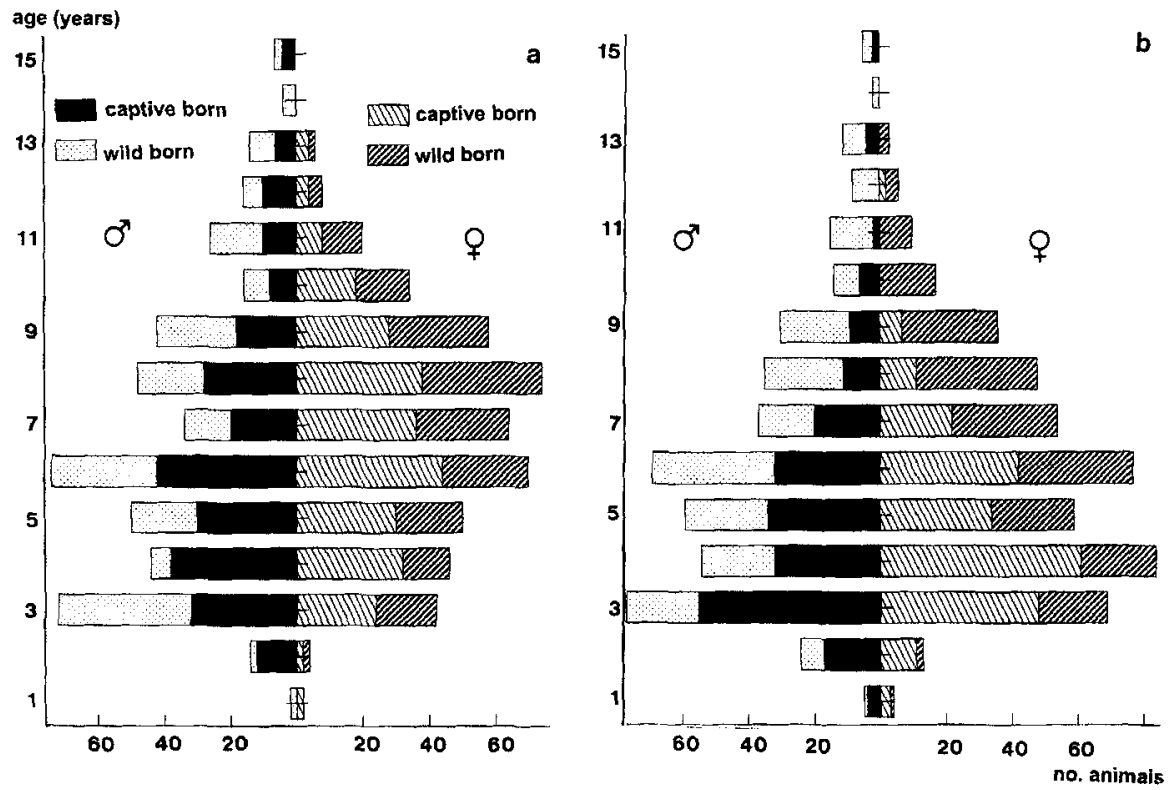

Fig. 4. Age distribution of successfully breeding Cheetahs at a. first litter and b. last litter.

equally distributed from 2 to 17 years of age. This could suggest that once wild Cheetahs survive to an age when they can be brought into captivity they live over 4 years longer than captive-born animals. However, the age of wild-caught animals is seldom known and no allowance has been made any inaccuracies in estimating age. All dates refer to the time between arrival in captivity and the date of death, thus longevity for wild-caught animals only gives a reference of life span in captivity.

Comparing age of death for all animals from 1829 to 1994 (Fig. 7) and age at death in 1994 (Fig. 8) reveals that longevity has increased. The mean age at death calculated for all animals was $6 \cdot 1$ years, with wild-caught animals at $8 \cdot 2$ years and captive-born animals at 4.5 years. Mean age at death calculated for all animals over 1 year of age was 8.3 years, with wild-caught animals at 8.4 years and captive-born animals at 8.0 years. Using a two-tailed $T$-test for both of these parameters there was no statistically significant difference.
At London Zoo between 1930 and 1960 $45 \%$ of all Cheetahs survived less than 1 year. Mean longevity for Cheetahs which survived the first year was 3 years and 9 months. Maximum life span for a Cheetah at this time was 8.5 years. In 1976 a survey conducted by Amsterdam Zoo revealed that longevity in captivity had increased. Between 1947 and 1966, $74 \%$ of Cheetahs died before 5 years of age whereas between 1967 and 1974, only $44 \%$ died before 5 years of age. Although this suggests that longevity had increased between 1967 and 1974 only $21 \%$ of the captive Cheetah lived for 10 years. Between 1829 and 1994931 animals $(23 \%)$ of the registered and known Cheetahs in captivity $(n=4054)$ lived over 10 years. At time of writing the longevity record for a captive Cheetah is 21 years of age and 56 animals have lived over 17 years.

Post-mortem reports and information from individual institutions reported causes of death for 1630 animals of which $364(22 \%)$ represented mortality in animals under 6 months old. In cubs under 1 month old the main causes of 


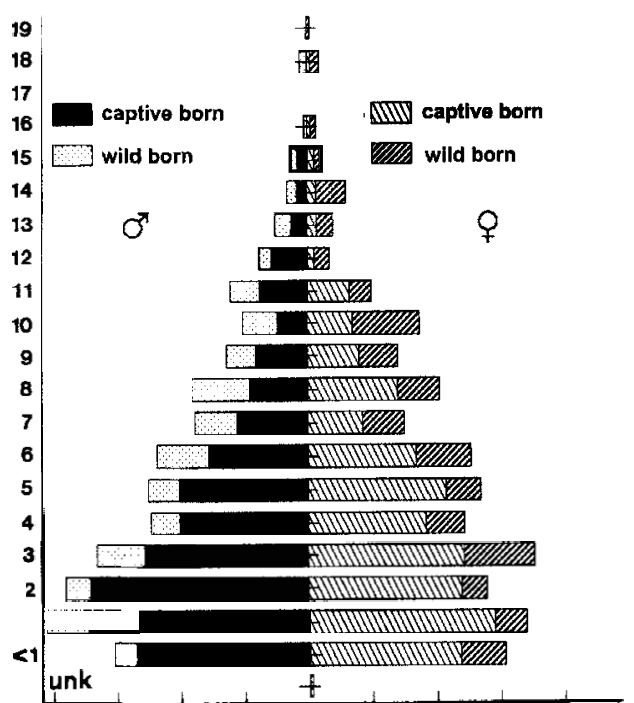

death were undetermined or miscellaneous $(24 \%)$, and still births $(20 \%)$ (Table 6$)$.

The predominant causes of death in animals over 6 months old $(n=1266)$ were kidney disease $(15 \%)$ and gastro-intestinal disorders, including enteritis, Escherichia coli and colitis (9\%), which have only recently been identified as major problems in captive Cheetah (Munson, 1993) (Table 7). Feline infectious peritonitis (FIP), a fatal coronavirus disease, was responsible for $6 \%$ of deaths. FIP is difficult to diagnose and, although it may have been present earlier, it was not recognized until 1982 (Pfeifer et al., 1983, O'Brien et al., 1985; Evermann et al., 1988). A common symptom of FIP is kidney and/or liver disease which account for $21 \%$ of mortality in captive Cheetah. Surveillance of this virus has continued and the number of sero-positive Cheetah in the North American population has increased from $35 \%$ in 1989 to $60 \%$ in 1990 (Evermann \& McKeirnan, 1991; Grisham \& Killmar, this volume).

\section{FOUNDERS AND PRESENT GENETIC}

STRUCTURE

Of the 1579 wild-caught Cheetahs that were imported between 1829 and 1994, $308(20 \%)$ reproduced and 155 of these have living descendants. Of 2517 captiveborn animals, 1208 reached reproductive age and $286(24 \%)$ of these have bred. The breeding frequency of captive-bred animals $(24 \%)$ versus wild-caught $(20 \%)$ animals suggests that subsequent generations of captive-bred Cheetahs should breed as well if not better than their wildcaught progenitors.

All founders in the current captive population are from the southern African subspecies Acinonyx jubatus jubatus, except 3.4 East African Cheetahs Acinonyx raineyi. Two East African founders have not contributed to the captive population because none of their offspring have survived. The other five have bred and in 1994 there were numerous hybrids in the population. Over the last few years the representation of two of the East African founders, stdbk no. 333 and stdbk

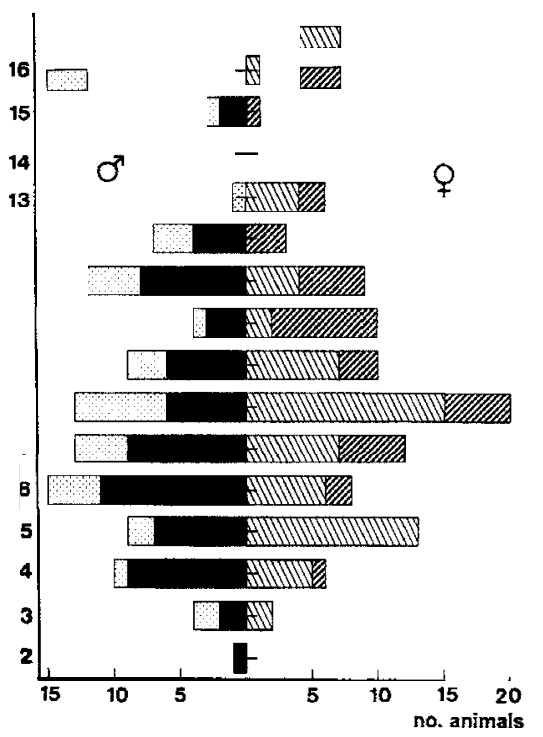

Fig. 6. Age distribution of proven breeding Cheetahs living as at 31 December 1994. 


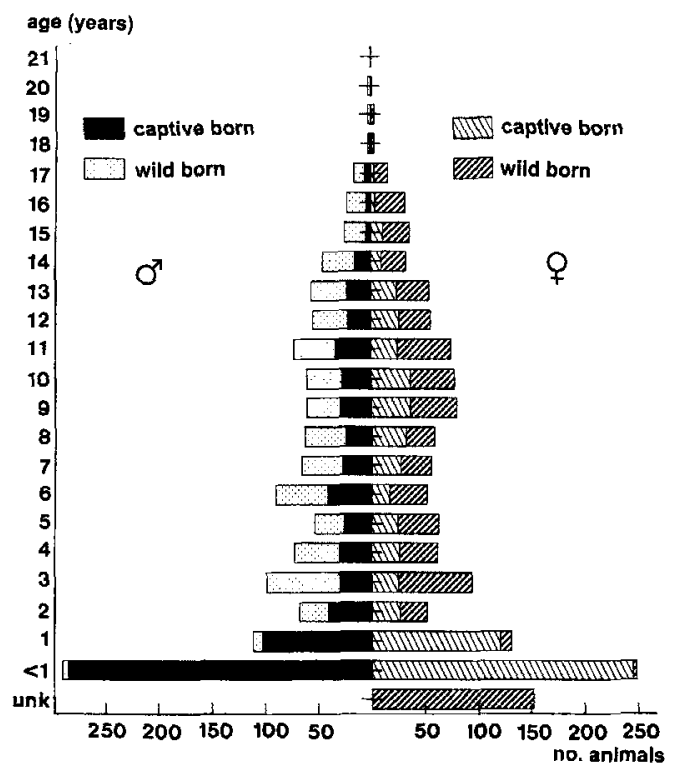

Fig. 7. Age distribution of mortality in Cheetahs between 1829 and 1994.

no. 353, has increased in Europe and North America.

Between 1990 and 199427 (10.17) hybrids produced 190 cubs, $24 \%$ of births for that period. Hybrids represent $13 \%$ of the breeding population. Using a twotailed $T$-test to compare the reproductive success between hybrids and the southern African subspecies revealed a significant difference between the total number of cubs born to hybrids $(P \leqslant 0.009)$ although there was no significant difference in rates of infant mortality.

Between 1990 and $199432 \%$ of Cheetahs which bred were wild-caught. During this period 174 wild-caught animals were imported of which $71(41 \%)$ have bred which indicates that the animals imported more recently have bred more successfully than those imported earlier.

Of the 308 wild-caught animals that have bred only 155 were represented in the 1994 population. Although the 1994 captive Cheetah population contained a large number of founders $(n=424), 269$ of these are wild-caught animals that are alive and have not yet produced offspring.
Of 338 wild-caught animals alive in the captive population in 1994 only $69(20 \%)$ are proven breeders.

Between 1990 and 1994812 cubs were born which represents $32 \%$ of total births between 1956 and 1994 (Table 2). A relatively small number of Cheetahs have made a disproportionally large contribution to the 1994 population gene pool: of the 812 young born eight of sired 173 $(21 \%)$ and 12 \& produced $195(24 \%)$ of the cubs.

\section{REGIONAL CAPTIVE BREEDING}

Southern Africa and North America have both produced about $30 \%$ of cubs while Australia and New Zealand, and North Africa (Morocco) only produced 2\% collectively (Table 8). Regional breeding success is important in relation to the number of animals actually living in the population (Table 3 ). In $199428 \%$ of the captive population was in southern Africa, most of which were wild-caught. North America maintained $27 \%$ of the population, $98 \%$ of which was captive-born. The higher breeding success in North 
America may be attributed in part to the SSP co-operative management programme which was developed in 1984 (Grisham, this volume).

Within each region there has been at least one facility that has had particular breeding success. In southern Africa, the DeWildt Cheetah Breeding and Research Centre has produced the most cubs $(n=395) \quad 16 \%$ of all births and $57 \%$ of cubs born in the region (Table 9). The success of particular facilities could be related to the large enclosures provided for animals which may reduce stress levels and increase the chances for successful breeding (see also Beekman et al., this volume; Bircher \& Noble, this volume). These facilities also hold large numbers of animals, which may allow for more opportunity for mate choice and other social factors which influence breeding (Table 9).

Regional breeding success should be monitored to facilitate co-operation between institutions and the transfer of animals within regions. One region may have greater founder representation than

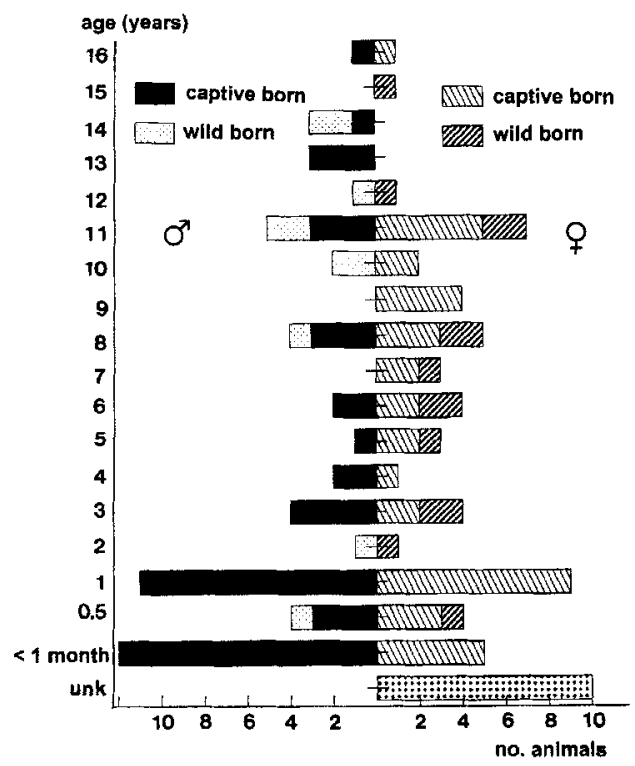

Fig. 8. Age distribution of mortality in Cheetahs in 1994.

\begin{tabular}{lll}
\hline CAUSE OF DEATH & No. & $\begin{array}{l}\% \text { TOTAL } \\
\text { ANIMALS }\end{array}$ \\
& MORTALITY \\
\hline Mortality <30 days & 89 & 24 \\
Stillborn & 72 & 20 \\
Eaten by adult & 68 & 19 \\
Maternal neglect & 60 & 17 \\
Nutritional deficiency & 25 & 7 \\
Congenital defect & 19 & 5 \\
Exposure & 14 & 4 \\
Aggression & 9 & 2 \\
Trauma & 8 & 2 \\
\hline
\end{tabular}

Table 6. Reported cause of death in captive Cheetah $<6$ months of age $(n=364)$ between 1829-1994.

another and over-represented animals in one region may be extremely important in others.

Outbreeding within the present population should be optimized in order to mask the potential deleterious physiological effects of inherent inbreeding (Marker \& O'Brien, 1989). This strategy could be extended by the introduction of new animals of different genetic lineages, preferably from the present captive population.

\section{DISCUSSION}

Despite an overall increase in the captive Cheetah population the age/sex distribution is not stable and the effective population size $\left(\mathrm{N}_{\mathrm{e}}\right)$ is low. The captive population is in need of a global-demographic and genetic-management programme. The critical objectives of this programme are equalizing founder representation and stabilizing the age/sex distribution within the captive population which, without a stable age distribution, could fluctuate detrimentally (Foose, 1980, 1983).

Although management of Cheetahs has improved and captive breeding has increased in 1994 only $10 \%$ of facilities bred the species, compared with $14 \%$ in 1984. Because 14 institutions have produced $63 \%$ of all cubs a disproportionate number of founders are represented. Therefore, there is a substantial need to 


\begin{tabular}{|c|c|c|}
\hline CAUSE OF DEATH & $\begin{array}{l}\text { NO. } \\
\text { ANIMALS }\end{array}$ & $\begin{array}{l}\% \text { TOTAL } \\
\text { MORTALITY }\end{array}$ \\
\hline Kidney disease & 184 & 14 \\
\hline $\begin{array}{l}\text { Gastro-intestinal (incl. } \\
\text { enteritis, Escherichia coli, } \\
\text { colitis) }\end{array}$ & 109 & 9 \\
\hline $\begin{array}{l}\text { Trauma (incl. accidents, } \\
\text { ruptures) }\end{array}$ & 98 & 8 \\
\hline $\begin{array}{l}\text { Respiratory (incl. } \\
\text { pneumonia, lung } \\
\text { diseases) }\end{array}$ & 95 & 7 \\
\hline $\begin{array}{l}\text { Liver (incl. hepatitis, veno- } \\
\text { occlusive disease) }\end{array}$ & 78 & 6 \\
\hline Feline infectious peritonitis & 74 & 6 \\
\hline Miscellaneous & 69 & 5 \\
\hline Infection & 67 & 5 \\
\hline Senescence & 52 & 4 \\
\hline Panleucopaenia & 48 & 4 \\
\hline Euthanasia/unknown & 47 & 4 \\
\hline Unknown & 46 & 4 \\
\hline Aggression & 41 & 3 \\
\hline Heart & 30 & 2 \\
\hline Muscular/skeletal & 28 & 2 \\
\hline Liver/kidney disease & 26 & 2 \\
\hline Cancer & 26 & 2 \\
\hline Peritonitis & 21 & 2 \\
\hline Poison/toxin & 21 & 2 \\
\hline Nutritional deficiency & 18 & 1 \\
\hline Pancreatitis & 16 & 1 \\
\hline Parasites & 15 & 1 \\
\hline Central nervous system & 12 & 1 \\
\hline Tuberculosis & 12 & 1 \\
\hline Spleen & 9 & 1 \\
\hline Tumour & 9 & 1 \\
\hline Haemorrhage & 8 & 1 \\
\hline Anaemia & 7 & 1 \\
\hline
\end{tabular}

Table 7. Reported cause of death for captive Cheetah $>6$ months of age $(n=1266)$ between 1829-1994.

continue enhancing management to ensure optimal captive breeding.

Inherent genetic impoverishment and husbandry problems contribute to the low $\mathrm{N}_{\mathrm{e}}(17 \%)$ in the captive population. The only way to improve the $\mathrm{N}_{\mathrm{c}}$ is to increase the size of the breeding population. This should not affect the remaining freeranging populations and it is recommended that new blood lines are obtained from captive-born animals instead of from the wild. Breeding facilities should cooperate to assist the movement of animals internationally.
Since the first captive birth in 1956, half the breeding founders or their offspring have died, but because of the importation of wild-caught animals potential founder numbers have increased by 116 animals in the 1994 population. These potential founders have a wide genetic background (Namibia, South Africa, East Africa and Zimbabwe) and could contribute a maximum amount of the existing genetic diversity to future offspring. However, equalizing founder representation is critical for optimal genetic management. Certain Cheetahs are disproportionately represented and a management plan should recommend that the more prolific Cheetahs be replaced with previously unrepresented lineages. The captive Cheetah population is grouped into small sub-populations in different countries. It is possible and highly preferable to outbreed with these other populations to reduce the possibility of inbreeding. This may be achieved by co-ordinated transfers between regions or by using artificial reproduction strategies (Caldwell \& Howard 1991; Howard et al., 1992; Grisham, this volume; Wildt \& Roth, this volume). Such recommendations can only be made after a systematic and thorough analysis of the objectives and realities of an international co-operative geneticmanagement programme.

In recent years, Great Britain, the Netherlands and South Africa have been the primary importers of wild Cheetahs. More emphasis should be placed on transferring potential founders between regions; for example, Cheetahs in the North American population could be exported to other regions which may create new bloodlines. If institutions collaborate in (1) the managed reproduction of Cheetahs and (2) animal transfers that facilitate breeding priorities, then greater reproductive success may be achieved.

Although a few facilities have had significant breeding success the captive population is not self-sustaining and is being maintained through importation of 


\begin{tabular}{lccll}
\hline REGION & $\begin{array}{l}\text { No. } \\
\text { CUBS }\end{array}$ & $\begin{array}{l}\text { NO. } \\
\text { LITTERS }\end{array}$ & $\begin{array}{l}\text { NO. } \\
\text { FACILITIEs }\end{array}$ & $\begin{array}{l}\text { YEARS } \\
\text { BREEDING }\end{array}$ \\
\hline North America & 753 & 224 & 32 & $1956-1994$ \\
Southern Africa & 696 & 232 & 13 & $1970-1994$ \\
Europe & 528 & 149 & 29 & $1960-1994$ \\
United Kingdom & 321 & 86 & 10 & $1967-1994$ \\
Far East & 181 & 61 & 7 & $1980-1994$ \\
Australia/New Zealand & 23 & 10 & 3 & $1976-1993$ \\
N.E. Africa/Middle East/ & 15 & 5 & 2 & $1976-1983$ \\
$\quad$ India & & & & \\
\hline
\end{tabular}

Table 8. Regional breeding success of captive Cheetah between 1956 and 1994.

wild-caught animals, which goes against the current goals of zoological institutions and zoo associations. The number of cubs born cannot be used as the sole measure of reproductive success and the reproduction of those offspring must also be considered.

Captive-management guidelines and husbandry recommendations for breeding Cheetah, based on empirical observations from many facility managers, have been developed (Grisham, 1992). Additionally, recent success in assisted reproduction in Cheetahs suggests that techniques such as artificial insemination and the utilization of germ plasm rather than the transfer of living animals will be of great benefit to both practical and genetic management (Howard et al., 1992; Wildt \& Roth, this volume).

Reviewing the management strategies at facilities that report breeding may assist reproductive success at other facilities. Larger enclosures and a higher number of animals held at a collection may contribute to breeding success. Institutions that do not have the space or resources to meet these criteria could exhibit animals that are not suitable for breeding purposes, such as those which are too old or too young for breeding, over-represented animals and of groups which should be kept together for breeding purposes in the future. Genetically valuable animals should be moved to proven breeding facilities thus allowing greater opportunity for reproductive success.

As the free-ranging Cheetah population continues to decline and as genetic diversity of the remaining population diminishes, the captive and wild populations should be co-operatively managed. In the absence of further importations from the wild, the size of the captive population

\begin{tabular}{|c|c|c|c|c|c|}
\hline \multirow{2}{*}{$\begin{array}{l}\text { REGION } \\
\text { (NO. FACILITIES) }\end{array}$} & \multirow{2}{*}{$\begin{array}{l}\text { TOTAL NO. } \\
\text { CUBS BORN } \\
\text { IN REGION }\end{array}$} & \multirow[t]{2}{*}{ FACILITY } & \multirow{2}{*}{$\begin{array}{l}\text { NO. CUBS } \\
\text { BORN AT } \\
\text { FACILITY }\end{array}$} & \multicolumn{2}{|l|}{$\%$} \\
\hline & & & & $\begin{array}{l}\text { TOTAL } \\
\text { BIRTHS }\end{array}$ & $\begin{array}{l}\text { CUBS BORN } \\
\text { IN REGION }\end{array}$ \\
\hline Southern Africa (13) & 696 & DeWildt SA & 395 & 16 & 57 \\
\hline \multirow[t]{2}{*}{ North America (32) } & 753 & Winston USA & 127 & 5 & 17 \\
\hline & & San Diego WAP USA & 106 & 4 & 14 \\
\hline \multirow[t]{2}{*}{ United Kingdom (10) } & 321 & Whipsnade GB & 132 & 5 & 41 \\
\hline & & Fota Ire & 104 & 4 & 33 \\
\hline \multirow[t]{2}{*}{ Far East (7) } & 181 & Wakayamaken Jap & 79 & 3 & 43 \\
\hline & & Himeji Jap & 78 & 3 & 43 \\
\hline
\end{tabular}

Table 9. Specific breeding success of Cheetah at particular facilities on a regional basis between 1956 and 1994. 
could be expected to decline unless there is further improvement in captive breeding. This trend, coupled with the continuing decline of the wild population, leaves the species extremely vulnerable. With the expanding database on husbandry and genetic management combined with international co-operation, the future of the captive population appears promising. A global-management programme will be a critical component for the long-term survival of the species.

\section{ACKNOWLEDGEMENTS}

The author is indebted to Stephanie Rhodes, Kim Bendheim, Karen Terio, Michelle Pomroy and Katie Emmanuel for assisting in collecting the data from historical records; to Judy Perkins and Sandy Hurlbut for their discussions and critical reading of this manuscript; to Daniel Kraus and Roland Philips for years of assistance with the international studbook; to the Cheetah Conservation Fund, NOAHS Center of the National Zoological Park, the WILD Foundation and the Namibian Nature Foundation for support of the international studbook.

\section{REFERENCES}

Brown, E. W., Olmsted, R. A., Martenson, J. S. \& O'Brien, S. J. (1993): Exposure to FIV and FIPV in wild and captive cheetahs. Zoo Biology 12: 135-142.

Caldowell, H. \& Howard, J. (1991): First cheetah cub produced by artificial insemination. Communiqué October: 13.

CARo, T. M. (1987): Cheetah mothers' vigilance looking out for prey or for predators. Behavioural Ecology and Sociobiology 20: 351-362.

Caro, T. M. (1993): Behavioral solutions to breeding cheetahs in captivity: insights from the wild. Zoo Biology 12: 19--30.

CITES (1984): Convention on International Trade in Endangered Species of wild fauna and flora, part of the endangered species act. Code Federal Register Part 23

CITES (1992): Quotas for trade in specimens of cheetah. Eighth meeting of the Convention of International Trade in Endangered Species of wild fauna and flora. Document 8.22 (Rev.): 1-5.

Dierenfeld, E. S. (1993): Nutrition of captive cheetahs: food composition and blood parameters. Zoo Biology 12: 143-150.

Divyabhanusinh (Unpublished): The origin, range and status of the Asiatic (or Indian) cheetah or hunting leopard (Acinonyx jubatus veneticus). Unpublished report presented at the IUCN Cat Specialist Group meeting at Kanha National Park, Madha Pradesh, India, 1984.
Everman,, J. F. \& McKeirnan, A. J. (1991): Infectious disease surveillance in the cheetah with primary emphasis on feline coronavirus and feline herpesvirus infections. American Association of Zoo Veterinarians Annual Proceedings 1991: 191-197.

Evermann, J. F., Heeney, J, L., Roelke, M. E., McKeirnan, A. J. \& O'Brien, S. J. (1988): Biological and pathological consequences of feline infectious peritonitis virus infection in the cheetah. Archives of Virology 102: 155-171.

Evermann, J. F., Laurenson, M. K., McKeirnan, A. J. \& CARO, T. M. (1993): Infectious disease surveillance in captive and free-living cheetahs: an integral part of the Species Survival Plan. Zoo Biology 12: $125-133$.

Foose, T. J. (1980): Demographic management of endangered species in captivity, International Zoo Yearbook 20: 154-166.

Foose, T. J. (1983): The relevance of captive propagation to the conservation of biotic diversity. In Genetics and conservation: 374-401. SchonewaldCox, C. M., Chambers, S. M., MacBryde, B. \& Thomas, L. (Eds). Menlo Park, CA: Benjamin/ Cummings.

Grisham, J. (1992): AAZPA cheetah husbandry manual 2. Oklahoma: Oklahoma City Zoological Park.

GrishaM, J. \& LindBURG, D. (1988): Cheetah SSP research master plan. Oklahoma: Oklahoma City Zoological Park.

GUGGISBERG, C. A. W. (1975): Wild cats of the world. New York: Taplinger.

Hamilton, P. H. (1986): Status of the cheetah in Kenya, with reference to sub-Saharan Africa. In Cats of the world: biology conservation and management: 65-76. Miller, S. D. \& Everett, D. D. (Eds). Washington, DC: National Wildlife Federation.

HAYASHI, T. (1986): Japunese regional cheetah studbook. Shirahama: Adventure World.

Heeney, J. L., Evermann, J. F., McKejrnan, A. J., Marker-Kraus, L., Roelke, M. E., Bush, M., Wildt, D. E., Meltzer, D. G., Colly, L. \& O'Brien, S. J. (1990): Prevalence and implications of feline coronavirus infections of captive and freeranging cheetahs (Acinonyx jubatus). Journal of Virology 64: 1964-1972.

Howard, J. L., Donoghue, A. M., Goodrowe, K. L., Blumer, E., Snodgrass, K., Starnes, D., Tucker, M., Bush, M. \& WILdT, D. E. (1992): Successful induction of ovarian activity and laparoscopic intrauterine artificial insemination in the cheetah (Acinonyx jubatus). Journal of Zoo and Wildlife Medicine 12: 81-96.

Howard, J. G., Munson, L., McAloose, D., Kriete, M., Bush, M. \& WiLdT, D. E. (1993): Comparative evaluation of seminal, vaginal, and rectal bacterial flora in the cheetah and domestic cat. Zoo Biology 12: $81-96$.

Junge, R. E., Oller, R. E., Boever, W. J., Scherbe, G. \& SundberG, J. (1991) Persistent cutaneous ulcers associated with feline herpesvirus type 1 infec- 
tion in cheetah. Journal of the American Veterinary Medical Association 196: 1057-1058.

KraUs, D. \& Marker-Kraus, L. (1992): Current status of the cheetah (Acinonyx jubatus). In 1991 International cheetah (Acinonyx jubatus) studbook. Marker-Kraus, L. (Ed.). Washington, DC: Smithsonian Institution's National Zoological Park's NOAHS Center.

Laurenson, K. (1991): Cheetahs never win. $B B C$ Wildlife Magazine February: 99-105.

LAURENSON, M. K. (1993): Early maternal behaviour of wild cheetahs: implications for captive husbandry. Zoo Biology 12: 31-43.

LindburG, D. G. (1991): On getting cheetahs to reproduce. Cheetah News: Cheetah SSP Newsletter, Zoological Society of San Diego Center for Reproduction of Endangered Species 1991: 4-5.

Lindburg, D. G., Durrant, B. S., Millard, S. E. \& Oosterhuis, J. E. (1993): Fertility assessment of cheetah males with poor quality semen. Zoo Biology 12: 97-103.

MCKeEver, M. (1994): A first-class sergeant of the zoo. Zoonooz, San Diego Wild Animal Park January: 12-17.

MCKEOWN, S. (1992): Joint management of species group regional cheetah studbook. Carrigtwohill: Fota Wildlife Park.

MARKER. L. (1983): North American regional cheetah studbook. Winston: Wildlife Safari.

Marker, L. \& O'Brien, S. J. (1989): Captive breeding of the cheetah (Acinonyx jubatus) in North American Zoos (1871-1986). Zoo Biology 8: 3-16.

MARKER-KraUS, L. (1990a): 1988 International cheetah (Acinonyx jubatus) studbook. Washington, DC: Smithsonian Institution's National Zoological Park's NOAHS Center.

MARKER-KRAUS, L. (1990b): 1989 International cheetah (Acinonyx jubatus) studbook. Washington, DC: Smithsonian Institution's National Zoological Park's NOAHS Center.

MARKER-KRAUS, L. (1991): 1990 International cheetah (Acinonyx jubatus) studbook. Washington, DC: Smithsonian Institution's National Zoological Park's NOAHS Center.

MARKER-KraUS, L. (1992): 1991 International cheetah (Acinonyx jubatus) studbook. Washington, DC: Smithsonian Institution's National Zoological Park's NOAHS Center.

Marker-Kraus, L. (1993): 1992 International cheetah (Acinonyx jubatus) studbook. Washington, DC: Smithsonian Institution's National Zoological Park's NOAHS Center.

MARKer-KraUS, L. (1995): 1993 International cheetah (Acinonyx jubatus) studbook. Washington, DC: Smithsonian Institution's National Zoological Park's NOAHS Center.

MARKER-KRAUS, L. (1996): 1994-1995 International cheetah (Acinonyx jubatus) studbook. Washington, DC: Smithsonian Institution's National Zoological Park's NOAHS Center.
Marker-Kraus, L. \& Grisham, J. (1993) Captive breeding of cheetahs in North American zoos; 1987-1991. Zoo Biology 12: 5-18.

Marker-Kraus, L. \& KraUs, D. (1990): Status of cheetah in Namibia and Zimbabwe. Cat News 12: 1. Marker-Kraus, L, Kraus, D., Barnett, D. \& Hurlbut, S. (1996): Cheetah survival on Namibian farmlands. Windhoek: Cheetah Conservation Fund. MENotTI-RAYMOND, M. \& O'BRIEN, S. J. (1993); Dating the genetic bottleneck of the African cheetah. Proceedings of the National Academy of Sciences of the USA 90: 3172-3176.

MruLs, G. (1991): Thick bush and stronger predators complicate cheetah's hunt. Custos 19(12): 16-18.

Morsbach, D. (1987): Cheetahs in Namibia. Cat News 6: 26.

Munson, L. (1993): Diseases of captive cheetahs (Acinonyx jubatus): results of the cheetah research council pathology survey, 1989-1992. Zoo Biology 12: $105-124$.

MYERs, N. (1975): The cheetah, Acinonyx jubatus, in Africa. IUCN Monograph 4. Morges, Switzerland: IUCN.

MYers, N. (1986): Conservation of Africa's cats: problems and opportunities. In Cats of the world: biology, conservation and management: 437-446. Miller, S. D. \& Everett, D. D. (Eds). Washington, DC: National Wildlife Federation.

O'Brien, S. J. (1994): Perspective on conservation genetics: molecular ecology and evolution approaches and applications: 274-280. Scheirwater, B., Streit, B., Wagner, G. P. \& DeSalle, R. (Eds). Basel: Birkhauser Verlag.

O'Brien, S. J., Wrldt, D. E., Goldman, D., Merril, C. R. \& Bush, M. (1983): The cheetah is depauperate in genetic variation. Science 221: $459-462$.

O'Brien, S. J., Roelke, M. E., MARKer, L., Newman, A., Winkler, C. A., Meltzer, D., Colly, L., EvermanN, J. F., Bush, M. \& Wildt, D. E. (1985): Genetic basis for species vulnerability in the cheetah. Science 227: 1428-1434.

O'Brien, S. J., Wildt, D. E., Bush, M., Caro, T. M., FitzGibbon, C., Aggundey, I. \& Leakey, R. E. (1987): East African cheetahs: evidence for two bottlenecks? Proceedings of the National Academy of Sciences of the USA 84: 508-511.

Pfeifer, M. L., Evermann, J. F., Roelke, M. E., Gallina, A. M., OtT, R. L. \& McKeirnan, A. J. (1983): Feline infectious peritonitis in a captive cheetah. Journal of the American Veterinary Medical Association 183: 1317-1319.

Ralls, K. \& Ballou, J. (1982): Effects of inbreeding on juvenile mortality in some small mammal species. Journal of Laboratory Animals 16: 159-166.

Soulé, M., GIlpIN, M., Conway, W. \& Foose, T. (1986): The millennium ark: how long a voyage, how may staterooms, how many passengers? Zoo Biology 5: $101-114$.

WESTENDORF, W. (1966): Beitrage aus und zu den medizinisched Texten. ZAS 92: 133. 
WILDT, D. E. \& GRISHAM, J. (1993): Basic research and the cheetah SSP program. Zoo Biology 12: 3-4. Wildt, D. E., Bush, M., Howard, J. G., O'Brien, S. J., V $\Lambda \mathrm{N}$ DYK, A., Ebedes, H. \& BRand, D. J. (1983): Unique seminal quality in the South African cheetah and a comparative evaluation in the domestic cat. Biology of Reproduction 29: 1019-1025. Wildt, D. E., O'Brien, S. J., Howard, J. G., Caro, T. M., Roelke, M. E., Brown, J. L. \& Bush, M. (1987): Similarity in ejaculate-endocrine characteristics in captive versus free-ranging cheetahs of two subspecies. Biology of Reproduction 36: 351-360.

Wildt, D. E., Brown, J. L., Bush, M., Barone, M. A., Cooper, K. A., Grisham, J. \& Howard, J. G.
(1993): Reproductive status of cheetahs (Acinonyx jubatus) in North American zoos: the benefits of physiological surveys for strategic planning. Zoo Biology 12: 45-80.

WILSON, V. J. (1987): Distribution and status of cheetah in Zimhabwe. Report of the Chipangali Wildlife Trust for IUCN, Zimbabwe.

WrogemanN, N. (1975): Cheetah under the sun. Johannesburg: McGraw-Hill.

Manuscript submitted 22 January 1996; revised 8 November 1996

\title{
Breeding and observations on the behaviour of Cheetah
} at Wassenaar Wildlife Breeding Centre

\author{
SYLVIE P. A. BEEKMAN', MARTINE DE WIT', JAN LOUWMAN² \& \\ HANNEKE LOUWMAN ${ }^{2}$ \\ 'Section Male Fertility, Department of Herd Health and Reproduction, Faculty of \\ Veterinary Medicine, Utrecht University and ${ }^{2}$ Wassenaar Wildlife Breeding Centre, \\ Raaphorstlaan 28, 2245 BJ Wassenaar, The Netherlands
}

\begin{abstract}
The Wassenaar Wildlife Breeding Centre was formerly a part of Wassenaar Zoo but has been an independent institution since 1984. The Centre, which is not open to the public, has established a breeding protocol for Cheetah Acinonyx jubatus which has resulted in 58.54 births since 1980 . This paper describes the husbandry and breeding of Cheetahs and the development of cubs. Behavioural comparisons on Cheetahs at Wassenaar and five other institutions, and observations on the behaviour of two $7 x$ and the breeding behaviour of one $t$ are also described.
\end{abstract}

Key-words: captive felid management, cheetah, feline reproduction

In 1937 the private collection of P. W. Louwman was officially opened to the public as Wassenaar Zoo and in 1983 the Zoo was given semi-governmental status. In 1984 Wassenaar Wildlife Breeding Centre, formerly an off-exhibit part of the
Zoo, became an independent institution. In 1985 the Zoo was closed but the Centre remained unaffected.

The Wassenaar Wildlife Breeding Centre specializes in breeding threatened species, particularly those that need a quiet and undisturbed environment. Because there is no visiting public the visibility of the animals does not need to be considered and enclosures can be designed to provide optimal living conditions. The Centre also provides holding facilities for animals until they can be placed elsewhere.

As an increasing number of species become threatened in the wild, captive breeding, via co-ordinated breeding programmes, has become a valuable conservation tool. Furthermore, some animals which are born in captivity can be rein- 